\section{OPEN BIOLOGY}

royalsocietypublishing.org/journal/rsob

\section{Review}

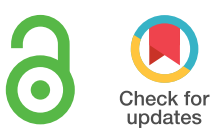

Cite this article: Harvey I, Boudreau A, Stephens JM. 2020 Adipose tissue in health and disease. Open Biol. 10: 200291. https://doi.org/10.1098/rsob.200291

Received: 9 September 2020

Accepted: 10 November 2020

\section{Subject Area:}

cellular biology/molecular biology

\section{Keywords:}

adipose tissue, obesity, insulin resistance, metabolic disease, type 2 diabetes, endocrine organ

\section{Author for correspondence:}

Jacqueline M. Stephens

e-mail: jsteph1@|su.edu

\section{Adipose tissue in health and disease}

Innocence Harvey ${ }^{1}$, Anik Boudreau ${ }^{1}$ and Jacqueline M. Stephens ${ }^{1,2}$

${ }^{1}$ Adipocyte Biology Laboratory, Pennington Biomedical Research Center, Baton Rouge, LA 70808, USA

${ }^{2}$ Department of Biological Sciences, Louisiana State University, Baton Rouge, LA 70803, USA

iD) IH, 0000-0002-5802-1010; AB, 0000-0002-5988-4694; JMS, 0000-0002-3796-9531

Adipose, or fat, tissue (AT) was once considered an inert tissue that primarily existed to store lipids, and was not historically recognized as an important organ in the regulation and maintenance of health. With the rise of obesity and more rigorous research, AT is now recognized as a highly complex metabolic organ involved in a host of important physiological functions, including glucose homeostasis and a multitude of endocrine capabilities. AT dysfunction has been implicated in several disease states, most notably obesity, metabolic syndrome and type 2 diabetes. The study of AT has provided useful insight in developing strategies to combat these highly prevalent metabolic diseases. This review highlights the major functions of adipose tissue and the consequences that can occur when disruption of these functions leads to systemic metabolic dysfunction.

\section{Introduction}

Adipose tissue (AT) is now fully recognized as a metabolically active organ. Historically, AT was thought to provide fuel or insulation to organs, and to serve as a connective tissue. Studies in the last two decades have demonstrated that AT plays a critical role in systemic metabolic health. While AT is indeed the primary site for energy storage in the form of lipid, it is also a major endocrine organ, producing and secreting adipose-tissue-specific hormones known as adipokines. In addition to hormones, fat tissue secretes various forms of genetic material, lipid and proteins that all contribute to its substantial endocrine activity. AT also responds to a variety of circulating metabolites and hormones, including lipids, growth hormone, cortisol, insulin, catecholamines and many others. Moreover, AT is known to be a major metabolic organ, along with the liver and skeletal muscle, critical to maintaining proper glucose homeostasis [1]. Disruption in any one of the three primary functions of adipocytes (lipid storage, endocrine function and responsiveness to insulin) can have major impacts on overall metabolic health. Excess adiposity, or obesity, is a major risk factor in several disease states including type 2 diabetes, cardiovascular disease, hepatic steatosis and at least 13 types of cancers [2-5]. Although research in adipocyte biology and physiology has advanced dramatically in recent years, our understanding of the complex processes governing the role of AT in health and disease is still emerging. This review highlights our knowledge of AT pathologies and how they contribute to metabolic diseases, as well as gaps in our understanding of AT biology that require further study.

\section{Adipose tissue expansion and development}

\subsection{Cellular growth and development}

AT is the primary organ for the storage of lipids. Excessive lipid accumulation results in obesity, also known as excessive adiposity or AT expansion, which is driven by adipocyte hyperplasia and/or hypertrophy. Hyperplasia refers to the formation of new adipocytes from preadipocytes through adipogenesis, a highly complex and tightly regulated process involving many hormones and 
transcription factors [6], most notably peroxisome proliferator-activated receptor gamma (PPAR $\gamma$ ), which is absolutely required for adipocyte differentiation and is considered the master regulator of adipogenesis [7]. Although adipogenesis in vitro is well understood, the control of this developmental pathway in vivo, in the presence of other tissues and a plethora of circulating factors, is less understood, due in part to the limited methodologies available to study adipogenesis in vivo. However, recently developed model systems featuring fluorescent labelling of adipocytes have allowed for a more rigorous in vivo assessment of adipogenesis [8-10]. For example, Tang and colleagues were able to detect newly formed adipocytes with the use of the AdipoTrak mouse model and demonstrated that PPAR $\gamma$ agonist treatment enhances adipogenesis in vivo, supporting previously established in vitro studies [8]. Utilization of fluorescence-activated cell sorting and liquid chromatography-tandem mass spectrometry methods has led to the identification of several unique types of adipocyte progenitor cells in adipose tissue, and provided insight into adipocyte origin, development and heterogeneity in both mice and humans [11-13]. Furthermore, other recent technologies such as single-cell RNA sequencing have advanced our comprehension of the genes and processes governing adipocyte commitment of precursors, progenitors and adipocyte stem cells [14,15]. The study of adipogenesis in vivo is still an emerging field and we have much left to learn. A recent review provides a detailed overview of the complex nature of adipocytes, as well as other cells within adipose tissue, and highlights the advantages of using of single-cell RNA sequencing in the study of adipocyte biology and development [16]. Further utilization of these new methods will enhance our understanding of overall AT expansion.

It is well established that inhibiting adipogenesis in mice can lead to metabolic dysfunction. For example, loss of PPAR $\gamma$ inhibits adipocyte hyperplasia and total AT accumulation, while promoting adipocyte hypertrophy, insulin resistance and other markers of metabolic dysfunction [17]. PPAR $\gamma$ agonists not only promote adipocyte differentiation [18], but also improve overall glucose homeostasis and metabolic health [19-21]. Deuterium labelling has allowed for further study of adipogenesis in humans in vivo. In line with the studies above, there is evidence that PPAR $\gamma$ agonists promote femoral adipocyte differentiation and improve insulin sensitivity in humans [22]. New adipocytes resulting from PPAR $\gamma$-driven adipogenesis facilitate increased lipid storage in AT and are associated with reduced circulating lipids, enhanced glucose disposal and increased fat oxidation in diabetic patients $[8,23]$. Notably, this formation of new adipocytes is associated with reduced ectopic lipid storage and a decrease in other markers of metabolic syndrome in patients with fatty liver disease [24,25]. Although PPAR $\gamma$ agonists are highly effective insulin sensitizers for type 2 diabetes treatment, their clinical use has been drastically reduced in recent years due to considerable side effects, including weight gain, fluid retention, congestive heart failure and bone fractures [26-29]. Conversely, there is recent data to suggest that enhanced adipocyte turnover negatively impacts metabolic health [30]. However, as the authors indicated, these data are correlative and it is still unclear whether adipocyte death was a driver of the increased adipogenesis. Clearly, more research needs to be performed in this area.
In contrast to hyperplasia, hypertrophy is the enlargement of individual adipocytes by lipid accumulation. Hypertrophy can occur through uptake of dietary lipids from the circulation, or through the fatty acid synthesis pathway in adipocytes, known as de novo lipogenesis (reviewed in [31]). Many rodent studies have suggested that larger adipocytes are a characteristic of metabolic dysfunction [32-34]. This notion is supported by clinical studies reporting that increased adipocyte size is associated with insulin resistance, hepatic steatosis and other markers of metabolic dysfunction $[27,28,35]$. Similarly, adipocyte volume was higher in patients who did not show improvements in insulin resistance following bariatric surgery [36]. Adipocyte hypertrophy has also been associated with insulin resistance and inflammation in healthy patients who are genetically predisposed to type 2 diabetes [37]. While it is generally accepted that impaired adipogenesis and excessive adipocyte hypertrophy are drivers of insulin resistance in obese states, data from several mouse models indicate that the relationship between fat cell size and metabolic dysfunction is not straightforward, and that changes in metabolic parameters can occur in the absence of altered adipocyte size, and vice versa. For example, ablation of Siah2, a ubiquitin ligase, results in obesity and enlarged adipocytes, but preserved insulin sensitivity [38]. Conversely, adipocyte-specific mTORc1 depletion in mice leads to smaller adipocytes accompanied by systemic insulin resistance [39]. Similarly, mice with ectopic expression of nuclear SREBP-1c in adipocytes have overt metabolic dysfunction and lipodystrophy, despite having notably smaller adipocytes when compared to controls [40]. Mice lacking collagen VI have large adipocytes due to uninhibited expansion, but have substantially improved whole-body energy and glucose homeostasis [41]. Also, a mouse model with ectopic expression of endotrophin, a proinflammatory adipokine, in adipocytes displayed increased AT inflammation and fibrosis, as well as systemic metabolic dysfunction, while adipocyte size was unchanged [42]. These data and many other examples make it clear that fat cell size is not an absolute indicator of systemic metabolic health. Overall, a balanced combination of adipocyte hypertrophy and hyperplasia is required for appropriate AT expansion and maintenance of metabolic health.

\subsection{Extracellular development}

Angiogenesis and vascularization are also important contributors to AT development, as they are required not only for oxygenation, but also for endocrine functions and nutrient transport to and from AT. Insufficient vascularization during AT expansion promotes hypoxia, which may trigger further complications including inflammation, fibrosis and apoptosis [43], contributing to adipose tissue dysfunction (figure 1). While many proteins participate in AT remodelling during expansion, vascular endothelial growth factor (VEGF) is considered the primary player in this process [44]. Several rodent studies demonstrate that reduced AT vascularity in obesity leads to systemic metabolic dysfunction. For example, mice with adipocyte-specific deletion of VEGF that are exposed to high-fat feeding have reduced vascularity, increased inflammation and significantly reduced glucose handling abilities despite a reduction in fat mass [45]. Notably, adipocyte overexpression of VEGF reverses these outcomes [45]. Several review articles have highlighted the 


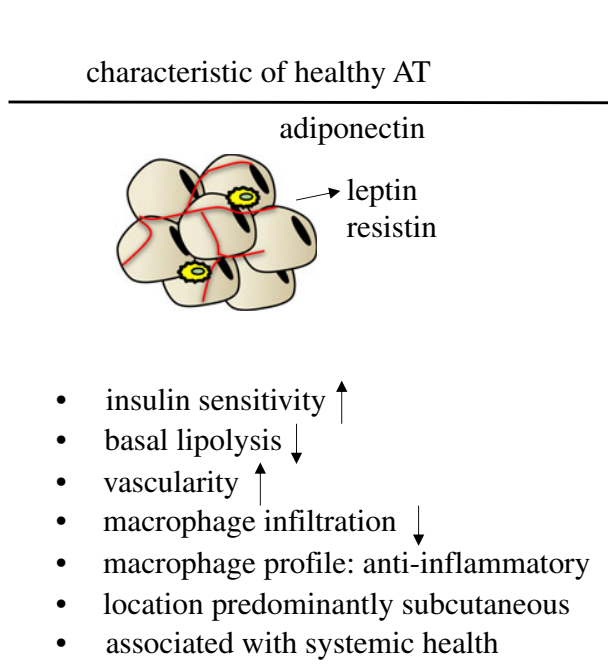

characteristic of compromised AT

Figure 1. General classifications of metabolically healthy and unhealthy white adipose tissue (AT). Metabolically healthy AT is generally stored subcutaneously, is highly vascularized with low levels of macrophages and has appropriate adiponectin secretion. Healthy adipocytes also have less production and secretion of leptin and resistin. Healthy adipocytes are insulin sensitive with low basal lipolysis that is associated with overall systemic metabolic health. In contrast, metabolically compromised AT is primarily stored in the visceral cavity, has reduced vascularity with increased infiltration or presence of proinflammatory macrophages, and enhanced secretion of leptin and resistin. Typically, unhealthy adipocytes are insulin resistant and have increased basal lipolysis. The increased fatty acids from lipolysis contribute to systemic metabolic dysfunction.

implications of impaired VEGF signalling in obesity-induced metabolic disease in humans [46,47]. The anti-angiogenic transcription factor forkhead box O1 (FOXO1) and the angiogenic adipokine neuroregulin 4 (NRG4) are also known to contribute to vascular regulation. FOXO1 levels are elevated in obesity, and mice with reduced endothelial expression of FOXO1 had improved vascular remodelling in AT and enhanced glucose tolerance [48]. However, the FOXO1deficient mice also had reduced body and fat mass, confounding the interpretation of these findings. NRG4 has recently been recognized as a pro-angiogenic adipokine [49]. Constitutive expression of NRG4 in adipocytes leads to improved glucose tolerance, increased adipose blood vessel formation and reduced hypoxia in AT of obese mice when compared to control mice of the same body weight [49]. Moreover, pharmacological inhibition of angiogenesis or blockade of the NRG4 receptor (ErbB) in the transgenic mice prevented the enhancement of angiogenesis and the favourable metabolic effects noted above [49]. These data suggest that NRG4-induced angiogenesis is a positive regulator of metabolic health in AT. Taken together, these data underscore the notion that AT development as a whole is crucial to systemic health.

\section{Inflammation}

Inflammation is a normal and necessary acute physiological response to a variety of stimuli, such as injury, but is often chronically elevated in several disease states including obesity and metabolic dysfunction. AT inflammation has been extensively studied over the past decade, and obesity is known to be associated with chronic low-grade inflammation and metabolic disease [50-52]. Numerous proinflammatory molecules in AT are involved in obesity-related metabolic disease, including tumour necrosis factor alpha $(\mathrm{TNF} \alpha)$, interleukin 6 (IL6), monocyte chemoattractant protein 1 (MCP1) and various adipokines (reviewed in [53], and discussed below in 'Endocrine functions within adipose tissue').
A high-profile report of obesity-induced inflammation was a study in the early 1990s showing elevated TNF $\alpha$ expression in the AT of genetically obese mice [54]. TNF $\alpha$ is known to induce insulin resistance in adipocytes through several mechanisms, including downregulating the expression of both the insulin receptor and the insulin-sensitive glucose transporter [55,56], as well as impeding insulin signalling events, antagonizing PPAR $\gamma$ action and inducing expression of proinflammatory genes (reviewed in [57]). Conditions such as hyperinsulinaemia and excess circulating lipids result in the recruitment of macrophages and other immune cells to the AT (figure 1), where they act as primary drivers of inflammation through the production of various paracrine factors, including inflammatory cytokines such as TNF $\alpha$ and IL-6 [43,58-62]. In obesity, the chronic overproduction of these inflammatory mediators can cause impaired adipocyte insulin signalling, further inflammation and a continued deterioration of AT function [43,60,63]. Traditionally, macrophages have been classified as either M1 or M2. The M1 type is associated with a proinflammatory environment and enhanced secretion of proinflammatory cytokines from macrophages and adipocytes; whereas the M2 type is considered immunosuppressive and typically plays a more protective or restorative role following inflammatory insults [64]. However, in the last few years, studies have identified several subtypes within the M1/M2 classifications, as well as additional classifications including the newly defined obesity-associated, metabolically activated (MMe) and metabolically oxidized (Mox) macrophages [62,65]. Moreover, new techniques such as single-cell RNA sequencing allows for highly sophisticated analysis of the cellular composition within adipose tissue and has revealed that immune cells represent a substantial percentage of adipose tissue cells and encompass an even greater variety than previously thought $[15,66]$. The understanding of the contributions of adipose tissue macrophages to adipocyte function and metabolic regulation continues to be an active and expanding area of research.

Inflammasomes, which also contribute to AT inflammation, are also known to influence glucose homeostasis. 
These multiprotein complexes promote the maturation and secretion of inflammatory cytokines and mediate inflammatory responses to a variety of stress signals, including microbial infection, as well as endogenous mediators such as free fatty acids or extracellular ATP (reviewed in [67]). The most thoroughly characterized is the NLRP3 inflammasome, which is associated with AT inflammation and systemic insulin resistance [67-71]. Its components include a Nod-like receptor (NLR), caspase-1 and apoptosis-associated speck-like protein containing a CARD (ASC) adaptor protein. Whole-body knockouts of inflammasome components have alleviated metabolic disturbances from dietinduced obesity [72,73]; however, these global knockouts also result in reduced body weight and fat mass, complicating the overall interpretation of the metabolic data. More recently, macrophage-specific knockouts have been developed and have yielded similar results [74]. There is evidence to suggest these data are translatable to humans as monocyte-derived macrophages from newly diagnosed type 2 diabetics expressed higher levels of NLRP3, ASC and proinflammatory cytokines, including several interleukins and TNF $\alpha$, when compared to non-diabetic control macrophages [75]. Moreover, the release of proinflammatory cytokines was significantly elevated in the culture media as well as in the serum of diabetic patients at baseline and following stimulation from fatty acids, when compared to non-diabetic controls [75]. These findings are consistent with previous studies documenting macrophage infiltration into AT as a feature of obesity-associated metabolic dysfunction in mice [59]. While our understanding of AT macrophages and the involvement of other AT immune cells in metabolic health and disease continues to evolve, it is clear that proinflammatory conditions are implicated in the pathology of obesity and associated metabolic disease states. However, in a field that is rapidly changing, it is worth noting that some degree of inflammatory signalling appears to necessary for normal AT function. Two proinflammatory cytokines, $\mathrm{TNF} \alpha$ and oncostatin $\mathrm{M}$, are known to be required for proper AT expansion and maintenance of insulin sensitivity in mice [76-79]. Moreover, recent findings suggest that inhibition of a high-fat diet induced inflammation specifically in adipocytes interferes with proper glucose handling [80]. Although AT inflammation clearly has detrimental effects in obesity, it also has adaptive and homeostatic roles in AT expansion and function and its impact on systemic metabolic regulation.

\section{Location of lipid storage}

On the whole, excess adiposity poses an increased risk of developing metabolic syndrome [81] and type 2 diabetes $[82,83]$. However, there are individuals who have increased adiposity in the absence of metabolic dysfunction, and are considered metabolically healthy obese [84]. Clearly, factors beyond simple adiposity are involved in regulating systemic metabolic homeostasis (figure 1). It is recognized that AT is highly heterogeneous, and that its many functions are impacted by parameters such as its constituent adipocyte types and anatomical locations. First, it is important to understand that there are several different types of adipocytes and AT, each with unique metabolic profiles. These types include white, brown and beige (or 'brite') fat. White AT (WAT) is the most abundant, and is the main focus of this review. Its metabolic characteristics are largely dependent on its anatomical location, as discussed below. Brown AT (BAT) is characterized by its ability to generate heat by uncoupling fuel oxidation from ATP generation, a process of metabolic inefficiency that has been speculated to be favourable to weight loss. Beige/brite AT is a newer designation and typically refers to white AT that has acquired some characteristics of brown fat. There is controversy regarding beige fat. While a large body of literature suggests that beige fat is metabolically beneficial $[85,86]$, it has also been considered a stress response to a large variety of conditions $[87,88]$. The functional differences among the AT varieties are not only dependent on location or energy production and utilization, but also on differences in gene expression, lipid droplet size, innervation and mitochondrial density. BAT and beige AT biology and function have been extensively reviewed [89]. Adding to the complexity of AT biology, recent studies reveal significant heterogeneity within the individual AT depots that likely impacts overall function and metabolic health [15,90,91]. Characteristics of AT heterogeneity are an emerging area of investigation; therefore, our understanding is still in its infancy.

The anatomical location of AT also influences systemic metabolism and overall health. Fat depots found in humans are not metabolically or anatomically identical to those found in rodents [92]. This information should be considered when interpreting AT studies. In general, WAT depots are broadly categorized as subcutaneous (located under the skin) or visceral (surrounding internal organs), and these distinctions are widely used and accepted in the study of AT. Typically, subcutaneous AT is considered metabolically healthy, especially when located around the gluteal-femoral region [93]; whereas visceral AT is associated with inflammation and increased metabolic disease risk. Specifically, human clinical studies have reported strong positive correlations between visceral fat and metabolic syndrome components including HOMA-IR and triglycerides, as well as hepatic steatosis, fibrosis and inflammation [94-96]. Moreover, visceral fat is positively associated with cardiovascular disease [95] and inflammatory markers [94,97]. Patients with severe obesity that had an omentectomy (where less than $1 \%$ of total fat was removed) in addition to gastric banding had significantly improved glucose handling 2 years after surgery when compared to gastric banding control patients, without significant differences in weight [98]. However, it is important to note that while not statistically significant, the omentectomy group lost more weight and had significantly lower BMI, potentially confounding these data. Metabolic improvement from omental removal has also been observed in lean dogs where omentectomy resulted in enhanced glucose uptake when compared to sham-operated dogs without significant alterations in visceral or total adiposity [99]. Similarly, metabolic improvements are observed when visceral fat is removed from mice, but not from the removal of other AT depots [100]. Conversely, subcutaneous AT is generally positively associated with metabolic health. Findings across several studies indicate that subcutaneous AT is negatively correlated with circulating triglycerides, insulin and glucose in humans $[93,101]$. This is supported by evidence in obese rodents showing that transplantation of subcutaneous depots from the same mouse or a donor mouse into the visceral cavity improves metabolic profiles without altering total fat mass; however, this was not true of visceral 
depot transplants [102,103]. Collectively, these data suggest that the location of AT may be a stronger predictor of metabolic health than total fat mass is, and that large amounts of AT in the visceral cavity are detrimental.

One major hypothesis as to why visceral fat has such detrimental effects on metabolic health is its proximity to the portal vein, such that anything released from visceral depots, including fatty acids and inflammatory molecules, have direct access to the liver. This idea is referred to as 'the portal theory' (see review [104]). In contrast, subcutaneous fat depots drain into the vena cava and enter the systemic circulation. In support of this theory, one study showed that donor epididymal AT depot transplants into the mesenteric cavity of recipient mice (i.e. portal drainage) resulted in significant glucose intolerance, increased IL-6 expression and macrophage infiltration [105]. On the contrary, when a depot of equal size from the same donor was transplanted to the visceral side of the peritoneum of another littermate (i.e. caval drainage) modest improvements in glucose tolerance were observed. Interestingly, ablation of IL-6 prevented glucose disturbances and reduced other inflammatory markers in the portal-drained group, indicating that inflammatory mediators released from the visceral AT may play a significant role in the associated pathology. Another study in obese rats showed that mesenteric visceral fat, which drains into the portal vein and most closely resembles human visceral $\mathrm{AT}$, played a greater role in insulin resistance when compared to perirenal and epididymal fat depots (typically considered to be visceral depots in rodents, although they do not drain portally) [106]. These data further support AT location as a major driver of metabolic symptoms associated with AT dysfunction.

Though the data described in support of the portal theory are sound and rigorous, there is evidence that glucose disposal rate is negatively associated with the amount of subcutaneous fat, suggesting that subcutaneous depots can also contribute to poor glucose metabolism [107,108]. Intrinsic depot-specific properties, such as inflammatory profiles and lipolytic rates are difficult to separate from the potential impacts of anatomical position (such as portal versus caval drainage), and more research in this area is warranted to determine the relative contributions of these factors to metabolic health. Also, the characteristics of AT that are primarily responsible for improvements in metabolic health are still largely unknown. Hopefully, future research and methods will identify more specific drivers of metabolic health and disease. Nonetheless, we can conclude that both the metabolic profile and the location of fat tissue can substantially contribute to metabolic disease.

Finally, in instances where there is insufficient AT mass or elevated AT lipolysis (discussed in further detail below), lipids can be stored ectopically across several tissues resulting in metabolic dysfunction. This phenomenon is commonly observed in lipoatrophy, a condition in which there is very little AT present, thereby preventing proper lipid storage. As a consequence, individuals with lipoatrophy have elevated circulating lipids, as well as ectopic fat storage in the liver and muscle $[109,110]$, conditions that are commonly associated with impaired glucose homeostasis [111,112]. Indeed, ectopic lipid accumulation in cardiac and skeletal muscle can result in tissue-specific and systemic insulin resistance [113-117]. As a whole, these findings underscore the importance of proper lipid storage within the AT and away from internal organs or skeletal muscles.

\section{Adipose tissue lipolysis and insulin resistance}

Insulin resistance and the progression to type 2 diabetes are among the most common metabolic syndrome co-morbidities associated with obesity $[83,118]$. AT contributions to systemic insulin resistance have been previously addressed and are discussed throughout this review, but insulin resistance within the AT should also be considered when evaluating the role of AT in metabolic diseases. Although skeletal muscle is responsible for the majority of insulin-stimulated glucose uptake [119], proper insulin signalling in AT is also important for systemic regulation of blood glucose as revealed by a variety of different mouse models. For example, adipocyte-specific ablation of GLUT4, the primary glucose transporter responsible for insulin-stimulated glucose uptake in AT and muscle, impairs insulin signalling in liver and muscle, and induces systemic insulin resistance and glucose intolerance in mice [120]. Likewise, adipocyte-specific insulin receptor knockouts have similar basal glucose uptake, but significantly reduced insulin-stimulated glucose uptake in adipocytes when compared to controls [121]. Notably, these mice have improvements in systemic glucose tolerance and this discrepancy may be a result of an upregulation in other signalling pathways to combat the loss of adipocyte insulin signalling from congenital gene ablation. For instance, one study investigated the effects of insulin receptor (IR) and insulin-like growth factor 1 receptor (IGF1R) on outcomes of metabolic disease in chow-fed mice by generating adipocyte-specific inducible knockout (KO) models of one (IRKO or IGF-1RKO) or both of these receptors (double KO; DKO [122]). Despite all KO groups having similar or reduced fat mass when compared to controls (depot dependent), the IRKO and DKO mice displayed systemic insulin resistance and hepatic steatosis when compared to the control and IGF-1RKO groups, with the combined deletion of these receptors resulting in the greatest disturbances in glucose handling. These findings suggest that a compensatory mechanism may be activated in other insulin responsive tissues, potentially including non-insulin dependent signalling pathways, to combat systemic glucose intolerance when there are defects in insulin receptor signalling in the AT from birth. Nevertheless, these data indicate that proper insulin signalling within the AT is key for systemic health.

One way in which AT insulin sensitivity impacts systemic health is through regulation of AT lipolysis (the breakdown of triglycerides into free fatty acids and glycerol). Lipolysis is induced by adrenergic stimulation to mobilize energy stores in conditions such as fasting, exercise and stress. In the fed state, insulin inhibits lipolysis and promotes lipid storage. Disruption of insulin signalling in AT, therefore, can result in elevated basal lipolysis (reviewed in [123]). The chronic low-grade inflammation associated with obesity also contributes to excessive release of lipids by adipocytes, as the inflammatory cytokine TNF $\alpha$ can also induce lipolysis in a manner independent of insulin signalling (reviewed in [124] and [57]). Indeed, obesity and insulin resistance are known to be associated with high basal lipolysis rates (figure 1). The resulting increase in circulating fatty acid levels promotes further metabolic dysfunction through ectopic lipid accumulation, particularly in liver and muscle [123]. The vicious 


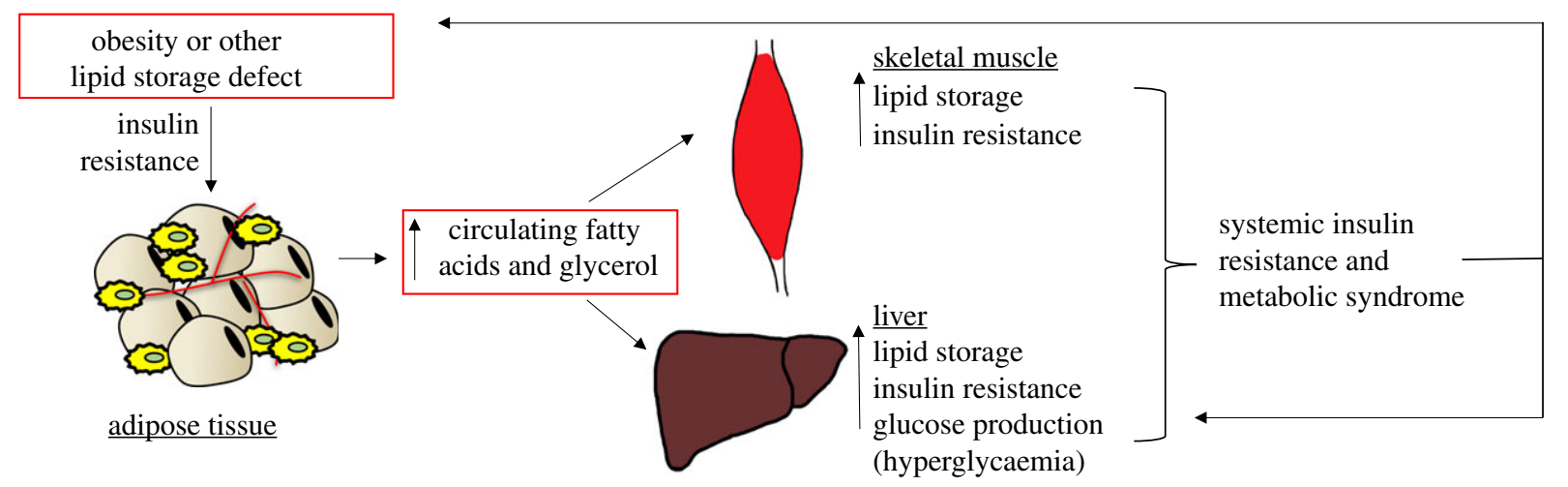

Figure 2. Contribution of adipose tissue dysfunction in the perpetuation of metabolic disease. Disturbances in lipid storage, such as in obesity or lipodystrophy, will interfere with proper adipocyte function and can contribute to insulin resistance. Insulin resistance within the adipose tissue will disrupt normal adipocyte signalling and metabolism resulting in elevated lipolysis. Chronically elevated circulating lipids can lead to ectopic lipid storage and insulin resistance in other tissues, including skeletal muscle and liver. Insulin resistance in the liver in particular is problematic as insulin signalling tightly regulates hepatic glucose production. All of these events can have significant consequences on metabolic health, ultimately resulting in a vicious cycle that perpetuates systemic metabolic disorder.

cycle of insulin resistance and elevated basal lipolysis in adipocytes is represented in figure 2. Type 2 diabetes and hepatic lipid accumulation are often observed in conditions associated with elevated basal lipolysis, including Cushing's syndrome $[125,126]$, as well as in conditions of lipoatrophy where there is an excess of circulating lipids [111]. Although AT may not be directly responsible for the majority of wholebody glucose uptake, it is clear that impaired glucose uptake and lipid storage in AT affect other insulin-responsive organs and thus modulate overall systemic health.

\section{Endocrine functions within adipose tissue}

In addition to being highly insulin-responsive, AT also secretes several molecules involved in glucose regulation and metabolic health (figure 1). These molecules, collectively known as adipokines, can be anti- or proinflammatory. Adipokines can act as endocrine regulators, released into the circulation and affecting several other tissues and organs, but can also regulate local signalling in a paracrine or autocrine manner. Several adipokines have now been discovered (reviewed in [127,128] [129]), but we will focus here on the three adipokines that are produced in mouse adipocytes: leptin, resistin and adiponectin. In 1994, leptin was the first adipocyte-derived endocrine hormone to be discovered. Leptin is released from adipocytes proportionally to AT mass and is acutely regulated by fasting [130-132]. In a normal physiological setting, high levels of leptin signal to the brain to cease food intake and, therefore, is known as an anorexigenic hormone [133-136]. An absence of leptin signalling due to genetic mutations in leptin or the leptin receptor leads to severe obesity from hyperphagia in both mice and humans [137], and restoration of signalling will reverse these effects $[138,139]$. Leptin's anorectic effects, and its ability to rescue obesity in deficient states initially fuelled enthusiasm that leptin would effectively combat obesity. However, leptin is positively correlated with adiposity in humans [140,141], and leptin resistance is a common occurrence in obese states $[141,142]$. Therefore, leptin treatment in individuals with obesity who exhibit adequate or even elevated leptin levels has not been as beneficial as once hoped. On the contrary, recent findings from two mouse models of reduced leptin expression exposed to high-fat diet suggest that lower levels of leptin during the progression of obesity are protective against weight gain as well as the associated metabolic dysfunction [143]. In fact, a recent review features several studies that support the notion that a reduction in leptin signalling in the context of obesity is associated with weight loss and metabolic improvements [144]. Moreover, leptin has been recognized as a proinflammatory adipokine, so not only is it not beneficial in enhancing weight loss in the general population, it can actually be detrimental to metabolic health when chronically elevated [145]. Collectively these data suggest that low, but sufficient leptin may be beneficial for maintaining metabolic health. Leptin has also been shown to regulate endogenous cortisol production, thereby indirectly modifying glucose homeostasis [146]. These data highlight the importance of leptin production and signalling in the regulation of food intake and body weight.

Resistin is a proinflammatory adipokine, so named for its ability to promote insulin resistance. It was discovered in 2001 in an effort to identify genes suppressed by the PPAR $\gamma$ agonist and antidiabetic drug, rosiglitazone [147]. Interestingly, this endocrine hormone was also identified by another laboratory as an inhibitor of adipogenesis, and named 'adipocyte-specific secretory factor (ADSF)'. Not surprisingly, given its relationship with insulin resistance, resistin is elevated in obesity in mouse and man [147,148]. Loss of resistin through gene ablation or inactivation improves glucose metabolism in obese mouse models $[149,150]$. Evidence indicates that resistin enhances the protein levels and activity of SOCS3, which is required for resistin's ability to reduce insulin signalling in adipocytes [151]. Though most of the data surrounding resistin are negative in terms of how it affects metabolic health, there is also evidence that resistin is important in the regulation of fasting blood glucose [152]. Therefore, it is likely that resistin is necessary for glycaemic control, further illustrating the importance of adipocyte endocrine function in sustaining metabolic health. It bears mention that while resistin is primarily secreted from adipocytes in rodents, macrophages are the predominant source of resistin in humans. Nevertheless, resistin's function remains the same across species [153,154].

Adiponectin, an endocrine hormone released by adipocytes, is known to have anti-inflammatory effects and can 
enhance insulin sensitivity in several tissues, most notably the skeletal muscle and liver. Adiponectin acts via two G protein-coupled receptors called Adipor1 and Adipor2 and highly expressed in muscle, liver and heart $[155,156]$. In contrast to leptin, adiponectin circulating levels are lower in obesity and type 2 diabetes [157]. Adiponectin exerts its anti-diabetic effects mainly through suppression of hepatic glucose production [158-160], but also enhances glucose uptake in skeletal muscle in vitro [161,162]. Administration of adiponectin significantly lowers blood glucose in diabetic mice without affecting insulin levels [158], and has not been shown to induce hypoglycaemia, an added benefit in the treatment of diabetes. Adiponectin can also act in an autocrine manner, as underscored by the fact that it was first discovered in an effort to identify genes involved in adipogenesis [163]. It has now been shown that adiponectin can increase insulin-independent and insulin-stimulated glucose uptake within primary rat adipocytes [164] and regulate lipid accumulation and glucose uptake within the adipocyte [165]. Adiponectin signalling is also important in cardiac muscle, as low hormone levels are associated with coronary artery disease [166]. Furthermore, adiponectin is reported to enhance multiple signalling events including antioxidant, vasodilation and anti-inflammatory activities thought to promote cardiomyocyte health $[167,168]$. However, it should be noted that there is some controversy regarding adiponectin and cardiac health, as high adiponectin levels have been linked to cardiac dysfunction [169]. Although still not widely recognized, AT is a bona fide endocrine organ, releasing hormones and participating in interorgan communication to regulate glucose homeostasis and systemic health.

\section{Emerging approaches to combat adipose tissue-derived metabolic dysfunction}

The studies described in this review highlight the substantial complexities associated with AT in health and disease. As described, alterations in any adipocyte function can be detrimental to overall health. However, as our knowledge of adipocyte biology has expanded, a variety of interventions have emerged as potentially viable therapeutic strategies to ameliorate these metabolic disturbances. Listed below are a few strategies that have recently been investigated to combat adipocyte-mediated contributions to systemic metabolic disease states.

\subsection{Exercise}

Exercise is known to be extremely beneficial for health, and it has been shown to improve glucose homeostasis [170,171]; however, AT-specific effects of exercise have not been studied until recently. There is now evidence that exercise may drive improvements in inflammatory profiles and insulin signalling in AT. Specifically, in a rat model of HFD-induced obesity, aerobic-interval exercise training significantly improved macrophage and inflammatory profiles, as well as capillary density in AT when compared with controls [172]. Moreover, transplantation of WAT from exercise-trained mice into sedentary mice significantly improved systemic glucose tolerance and insulin sensitivity in chow-fed and HFD-fed animals when compared to sham controls or transplantation of sedentary tissue from donor mice given the same diet [53].
Lastly, exercise-trained mice displayed significant elevations in the expression of genes involved in browning in their WAT [173], potentially enhancing energy expenditure and improving overall metabolism. These data suggest that exercise has direct effects on adipocytes that could mitigate the AT dysfunction associated with systemic metabolic perturbations.

\section{2. microRNAs}

microRNAs (miRNAs) are small non-coding RNAs that generally function as inhibitors of genes by binding to their target mRNA transcripts, thereby preventing gene translation and protein expression. These molecules were discovered in 1990, but AT has only recently been identified as a major source of circulating miRNAs [174]. The importance of miRNA expression and activity within the AT is a fairly new topic and still being explored; however, recent evidence indicates that they are crucial for maintenance of adipocyte function. An adipocyte-specific gene knockout of dicer (the enzyme involved in processing miRNAs) results in significant reductions in all WAT depots and severe insulin resistance [175]. Interestingly, with evidence that circulating miRNAs are altered in individuals with obesity and type 2 diabetes, miRNAs are now being considered as potential biomarkers of metabolic health in humans, and are being investigated as potential therapeutics in the treatment of metabolic disease (reviewed here [176]), clearly illustrating miRNAs as promising targets in the regulation of metabolic syndrome.

\subsection{Exosomes}

Exosomes are a particular type of extracellular vesicles that can transport a wide range of materials, including proteins, lipids, metabolites and different species of RNA. In recent years, exosomes have been identified as mediators of disease pathology and as potential therapeutics (reviewed in [177]). Adipose-derived exosomes are currently the subject of intense study, as they are now known to have a critical role in interorgan communication, and to modulate whole-body metabolism (reviewed in [178]). Recent evidence suggests that AT exosomes are significant transporters of circulating miRNAs [174]. A study in diet-induced obese mice showed that intraperitoneal injections of exosomes from isolated adipose-derived stem cells originating from the epididymal WAT of lean mice promoted a shift in macrophage polarization from M1 to $\mathrm{M} 2$ and resulted in significant reductions in markers of inflammation within the circulation [179]. Additionally, the administration of exosomes resulted in significant improvements in glucose tolerance, as well as significant reductions in hepatic lipid accumulation. Exosomes are also implicated in paracrine signalling within the AT, providing transport from different cell types and allowing for intra-organ communication. One group reported the surprising finding that caveolin-1 (Cav-1) protein was detected in adipocytes where the Cav1 gene had been successfully deleted [180]. It was determined that Cav-1 was being transported via exosome from nearby endothelial cells and taken up by the adipocytes. Furthermore, data from this paper also suggest that exosome production in response to stimuli such as the fasting/feeding transition is blunted in obesity. These studies support the use of exosomes as a treatment for metabolic disease. In fact, exosomes are currently being 
investigated for their ability to package and deliver microRNAs as therapeutics [176].

\section{Concluding remarks}

Novel methodologies and technical advances continue to drive the elucidation of complex mechanisms involved in the contributions of AT to health and disease. We have summarized the principal features of AT function and dysfunction in figure 1. In addition to the many unresolved questions we have discussed in this review, it should be noted that mechanistic data from animal models are largely derived from studies on male rodents, and that sex differences in metabolism and AT function are known to exist in rodents as well as humans [181,182]. Therefore, special emphasis should be placed on the study of sex differences in the context of AT in health and disease in the future. In conclusion, while much remains to be learned about how AT contributes to metabolic disease, there is no question that AT is central to systemic health and that disruption of any of its functions can have substantial impacts.

Data accessibility. This article has no additional data.

Authors' contributions. I.H. and J.M.S. identified relevant manuscripts to consider. I.H. wrote first draft of this review. I.H., A.B. and J.M.S. edited various versions of the manuscript.

Competing interests. We declare we have no competing interests.

Funding. We received no funding for this study.

\section{References}

1. Rosen ED, Spiegelman BM. 2006 Adipocytes as regulators of energy balance and glucose homeostasis. Nature 444, 847-853. (doi:10.1038/ nature05483)

2. Avgerinos Kl, Spyrou N, Mantzoros CS, Dalamaga M. 2019 Obesity and cancer risk: emerging biological mechanisms and perspectives. Metabolism 92, 121-135. (doi:10.1016/j.metabol.2018.11.001)

3. Polyzos SA, Kountouras J, Mantzoros CS. 2019 Obesity and nonalcoholic fatty liver disease: from pathophysiology to therapeutics. Metabolism $\mathbf{9 2}$, 82-97. (doi:10.1016/.j.metabol.2018.11.014)

4. Ortega FB, Lavie CJ, Blair SN. 2016 Obesity and cardiovascular disease. Circ. Res. 118, 1752-1770. (doi:10.1161/CIRCRESAHA.115.306883)

5. Bhupathiraju SN, Hu FB. 2016 Epidemiology of obesity and diabetes and their cardiovascular complications. Circ. Res. 118, 1723-1735. (doi:10. 1161/CIRCRESAHA.115.306825)

6. de Sá PM, Richard AJ, Hang H, Stephens JM. 2017 Transcriptional regulation of adipogenesis. Comp. Physiol. 7, 635-674.

7. Rosen ED, Sarraf $P$, Troy AE, Bradwin G, Moore $K$, Milstone DS, Spiegelman BM, Mortensen RM. 1999 PPAR $\gamma$ is required for the differentiation of adipose tissue in vivo and in vitro. Mol. Cell 4, 611-617. (doi:10.1016/S1097-2765(00)80211-7)

8. Tang W, Zeve D, Seo J, Jo AY, Graff JM. 2011 Thiazolidinediones regulate adipose lineage dynamics. Cell Metab. 14, 116-122. (doi:10.1016/j. cmet.2011.05.012)

9. Wang QA, Tao C, Gupta RK, Scherer PE. 2013 Tracking adipogenesis during white adipose tissue development, expansion and regeneration. Nat. Med. 19, 1338-1344. (doi:10.1038/nm.3324)

10. Wang QA, Scherer PE. 2014 The AdipoChaser mouse. Adipocyte 3, 146-150. (doi:10.4161/adip.27656)

11. Raajendiran $A$ et al. 2019 Identification of metabolically distinct adipocyte progenitor cells in human adipose tissues. Cell Rep. 27, 1528-1540.e7. (doi:10.1016/j.celrep.2019.04.010)

12. Jiang Y, Berry DC, Tang W, Graff JM. 2014 Independent stem cell lineages regulate adipose organogenesis and adipose homeostasis. (ell Rep. 9, 1007-1022. (doi:10.1016/j.celrep.2014.09.049)

13. Rampler E, Egger D, Schoeny H, Rusz M, Pacheco MP, Marino G, Kasper C, Naegele T, Koellensperger G. 2019 The power of LC-MS based multiomics: exploring adipogenic differentiation of human mesenchymal stem/stromal cells. Molecules 24, 3615.

14. Hepler C et al. 2018 Identification of functionally distinct fibro-inflammatory and adipogenic stromal subpopulations in visceral adipose tissue of adult mice. Elife 7, 1-36. (doi:10.7554/elife.39636)

15. Burl RB, Ramseyer VD, Rondini EA, Pique-Regi $R$, Lee YH, Granneman JG. 2018 Deconstructing adipogenesis induced by $\beta 3$-adrenergic receptor activation with single-cell expression profiling. Cell Metab. 28, 300-309. (doi:10.1016/j.cmet.2018.05. 025)

16. Rondini E, Granneman J. 2020 Single cell approaches to address adipose tissue stromal cell heterogeneity. Biochem. J. 477, 583-600. (doi:10 1042/BCJ20190467)

17. He W et al. 2003 Adipose-specific peroxisome proliferator-activated receptor $\gamma$ knockout causes insulin resistance in fat and liver but not in muscle. Proc. Natl Acad. Sci. USA 100, 15 712-15 717. (doi:10.1073/pnas.2536828100)

18. Chou FS, Wang PS, Kulp S, Pinzone JJ. 2007 Effects of thiazolidinediones on differentiation, proliferation, and apoptosis. Mol. Cancer Res. 5, 523-530. (doi:10.1158/1541-7786.MCR-06-0278)

19. Raji A, Seely E, Bekins S, Williams G, Simonson D. 2003 Rosiglitazone improves insulin sensitivity and lowers blood pressure in hypertensive patients. Diabetes Care 26, 172-178. (doi:10.2337/diacare.26. 1.172)

20. Mayerson $A B$ et al. 2002 The effects of rosiglitazone on insulin sensitivity, lipolysis, and hepatic and skeletal muscle triglyceride content in patients with type 2 diabetes. Diabetes 51, 797-802. (doi:10. 2337/diabetes.51.3.797)

21. Olefsky JM, Saltiel AR. 2000 PPAR $\gamma$ and the treatment of insulin resistance. Trends Endocrinol.
Metab. 11, 362-368. (doi:10.1016/S10432760(00)00306-4)

22. White U, Fitch MD, Beyl RA, Hellerstein MK, Ravussin E. In press. Adipose depot-specific effects of 16 weeks of pioglitazone on in vivo adipogenesis in women with obesity: a randomised controlled trial. Diabetologia.

23. Boden G, Homko C, Mozzoli M, Showe LC, Nichols C, Cheung P. 2005 Thiazolidinediones upregulate fatty acid uptake and oxidation in adipose tissue of diabetic patients. Diabetes 54, 880-885. (doi:10. 2337/diabetes.54.3.880)

24. Snyder HS et al. 2018 Non-alcoholic fatty liver disease: a review of anti-diabetic pharmacologic therapies. J. Clin. Transl. Hepatol. 6, 1-7. (doi:10. 14218/JCTH.2017.00050)

25. Lee YH, Kim JH, Kim SR, Jin HY, Rhee EJ, Cho YM, Lee B-W. 2017 Lobeglitazone, a novel thiazolidinedione, improves non-alcoholic fatty liver disease in type 2 diabetes: its efficacy and predictive factors related to responsiveness. J. Korean Med. Sci. 32, 60-69. (doi:10.3346/jkms.2017.32.1.60)

26. Harrington WW, Britt CS, Wilson JG, Milliken NO, Binz JG, Lobe DC, Oliver WR, Lewis MC, Ignar DM. 2007 The effect of PPAR $\alpha$, PPARS, PPAR $\gamma$, and PPARpan agonists on body weight, body mass, and serum lipid profiles in diet-induced obese AKR/J mice. PPAR Res. 2007, 1-13. (doi:10.1155/2007/ 97125)

27. Wright MB, Bortolini M, Tadayyon M, Bopst M. 2014 Minireview: Challenges and opportunities in development of PPAR agonists. Mol. Endocrinol. 28 1756-1768. (doi:10.1210/me.2013-1427)

28. Betteridge DJ. 2011 Thiazolidinediones and fracture risk in patients with type 2 diabetes. Diabet. Med. 28, 759-771. (doi:10.1111/j.14645491.2010.03187.x)

29. Nesto RW et al. 2003 Thiazolidinedione use, fluid retention, and congestive heart failure: a consensus statement from the American Heart Association and American Diabetes Association. Circulation 108, 2941-2948. (doi:10.1161/01.CIR. 0000103683.99399.7E) 
30. White UA, Fitch MD, Beyl RA, Hellerstein MK, Ravussin E. 2017 Association of in vivo adipose tissue cellular kinetics with markers of metabolic health in humans. J. Clin. Endocrinol. Metab. 102, 2171-2178. (doi:10.1210/jc.2016-4000)

31. Girard J, Perdereau D, Foufelle F, Prip-Buus C, Ferré P. 1994 Regulation of lipogenic enzyme gene expression by nutrients and hormones. FASEB J. 8, 36-42. (doi:10.1096/fasebj.8.1.7905448)

32. Okuno A et al. 1998 Troglitazone increases the number of small adipocytes without the change of white adipose tissue mass in obese Zucker rats. J. Clin. Invest. 101, 1354-1361. (doi:10.1172/JCI1235)

33. Jones MEE et al. 2000 Aromatase-deficient (ArKO) mice have a phenotype of increased adiposity. Proc. Natl Acad. Sci. USA 97, 12 735-12 740. (doi:10. 1073/pnas.97.23.12735)

34. Rong JX et al. 2007 Adipose mitochondrial biogenesis is suppressed in $d b / d b$ and high-fat diet-fed mice and improved by rosiglitazone. Diabetes 56, 1751-1760. (doi:10.2337/db06-1135)

35. O'Connell J, Lynch L, Cawood TJ, Kwasnik A, Nolan $\mathrm{N}$, Geoghegan J, Mccormick A, O'farrelly C, O'shea D. 2010 The relationship of omental and subcutaneous adipocyte size to metabolic disease in severe obesity. PLoS ONE 5, e9997. (doi:10.1371/journal. pone.0009997)

36. Cotillard A et al. 2014 Adipocyte size threshold matters: link with risk of type 2 diabetes and improved insulin resistance after gastric bypass. J. Clin. Endocrinol. Metab. 99, 1466-1470. (doi:10. 1210/jc.2014-1074)

37. Henninger AMJ, Eliasson $B$, Jenndahl LE, Hammarstedt A. 2014 Adipocyte hypertrophy, inflammation and fibrosis characterize subcutaneous adipose tissue of healthy, non-obese subjects predisposed to type 2 diabetes. PLOS ONE 9 e105262. (doi:10.1371/journal.pone.0105262)

38. Kilroy $\mathrm{G}$ et al. 2015 The ubiquitin ligase Siah2 regulates obesity-induced adipose tissue inflammation. Obesity 23, 2223-2232. (doi:10. 1002/oby.21220)

39. Shan $T$, Zhang $P$, Jiang $Q$, Xiong $Y$, Wang $Y$, Kuang S. 2016 Adipocyte-specific deletion of mTOR inhibits adipose tissue development and causes insulin resistance in mice. Diabetologia 59, 1995-2004. (doi:10.1007/s00125-016-4006-4)

40. Shimomura I, Hammer RE, Richardson JA, Ikemoto S, Bashmakov Y, Goldstein JL, Brown MS. 1998 Insulin resistance and diabetes mellitus in transgenic mice expressing nuclear SREBP-1c in adipose tissue: model for congenital generalized lipodystrophy. Genes Dev. 12, 3182-3194. (doi:10. 1101/gad.12.20.3182)

41. Khan T et al. 2009 Metabolic dysregulation and adipose tissue fibrosis: role of collagen VI. Mol. Cell. Biol. 29, 1575-1591. (doi:10.1128/MCB. 01300-08)

42. Sun $\mathrm{K}$ et al. 2014 Endotrophin triggers adipose tissue fibrosis and metabolic dysfunction. Nat. Commun. 5, 3485. (doi:10.1038/ncomms4485)

43. Crewe $C$, An YA, Scherer PE. 2017 The ominous triad of adipose tissue dysfunction: inflammation, fibrosis, and impaired angiogenesis. J. Clin. Invest. 127, 74. (doi:10.1172/JC(88883)

44. Sun K, Kusminski CM, Scherer PE. 2011 Adipose tissue remodeling and obesity. J. Clin. Invest. 121, 2094-2101. (doi:10.1172/JCI45887)

45. Sung HK et al. 2013 Adipose vascular endothelial growth factor regulates metabolic homeostasis through angiogenesis. Cell Metab. 17, 61-72. (doi:10.1016/j.cmet.2012.12.010)

46. Mazidi M, Rezaie P, Kengne AP, Stathopoulou MG, Azimi-Nezhad M, Siest S. 2017 VEGF, the underlying factor for metabolic syndrome; fact or fiction? Diabetes Metab. Syndr. Clin. Res. Rev. 11, S61-S64. (doi:10.1016/j.dsx.2016.12.004)

47. Gaspar JM, Velloso LA. 2018 Hypoxia inducible factor as a central regulator of metabolismimplications for the development of obesity. Front. Neurosci. 12, 1-12. (doi:10.3389/fnins.2018. 00813)

48. Rudnicki $\mathrm{M}$ et al. 2018 Endothelial-specific Fox01 depletion prevents obesity-related disorders by increasing vascular metabolism and growth. Elife 7, 1-25. (doi:10.7554/elife.39780)

49. Nugroho DB, Ikeda K, Kajimoto K, Hirata K, Emoto N. 2018 Activation of neuregulin-4 in adipocytes improves metabolic health by enhancing adipose tissue angiogenesis. Biochem. Biophys. Res. Commun. 504, 427-433. (doi:10.1016/j.bbrc.2018. 08.197)

50. Mraz M, Haluzik M. 2014 The role of adipose tissue immune cells in obesity and low-grade inflammation. J. Endocrinol. 222, 113-127. (doi:10. 1530/J0E-14-0283)

51. Saltiel AR, Olefsky JM. 2017 Inflammatory mechanisms linking obesity and metabolic disease. J. Clin. Invest. 127, 1-4. (doi:10.1172/ J(192035)

52. Zatterale F, Longo M, Naderi J, Raciti GA, Desiderio A, Miele C, Beguinot F. 2020 Chronic adipose tissue inflammation linking obesity to insulin resistance and type 2 diabetes. Front. Physiol. 10, 1607. (doi:10.3389/fphys.2019.01607)

53. Stanford Kl et al. $2015 \mathrm{~A}$ novel role for subcutaneous adipose tissue in exercise-induced improvements in glucose homeostasis. Diabetes 64, 2002-2014. (doi:10.2337/db14-0704)

54. Hotamisligil GS, Shargill NS, Spiegelman BM. 1993 Adipose expression of tumor necrosis factor- $\alpha$ : direct role in obesity-linked insulin resistance. Science 259, 87-91. (doi:10.1126/science.7678183)

55. Stephens JM, Pekala PH. 1992 Transcriptional repression of the C/EBP-alpha and GLUT4 genes in 3T3-L1 adipocytes by tumor necrosis factor-alpha. Regulations is coordinate and independent of protein synthesis. J. Biol. Chem. 267, 13 58013584.

56. Stephens JM, Lee J, Pilch PF. 1997 Tumor necrosis factor-alpha-induced insulin resistance in 3T3-L1 adipocytes is accompanied by a loss of insulin receptor substrate-1 and GLUT4 expression without a loss of insulin receptor-mediated signal transduction. J. Biol. Chem. 272, 971-976. (doi:10. 1074/jbc.272.2.971)
57. Cawthorn WP, Sethi JK. 2008 TNF- $\alpha$ and adipocyte biology. FEBS Lett. 582, 117-131. (doi:10.1016/j. febslet.2007.11.051)

58. Makki K, Froguel P, Wolowczuk I. 2013 Adipose tissue in obesity-related inflammation and insulin resistance: cells, cytokines, and chemokines. ISRN Inflamm. 2013, 1-12. (doi:10.1155/2013/139239)

59. Weisberg SP, McCann D, Desai M, Rosenbaum M, Leibel RL, Ferrante AW. 2003 Obesity is associated with macrophage accumulation in adipose tissue. J. Clin. Invest. 112, 1796-1808. (doi:10.1172/ $\mathrm{JC}(\mathrm{2} 200319246)$

60. Cinti $S$ et al. 2005 Adipocyte death defines macrophage localization and function in adipose tissue of obese mice and humans. J. Lipid Res. 46, 2347-2355. (doi:10.1194/Jr.M500294-JLR200)

61. Kratz M et al. 2014 Metabolic dysfunction drives a mechanistically distinct proinflammatory phenotype in adipose tissue macrophages. Cell Metab. 20, 614-625. (doi:10.1016/j.cmet.2014.08.010)

62. Ni Y, Ni L, Zhuge F, Xu L, Fu Z, Ota T. 2020 Adipose tissue macrophage phenotypes and characteristics: the key to insulin resistance in obesity and metabolic disorders. Obesity 28, 225-234. (doi:10. 1002/oby.22674)

63. Lumeng CN, Deyoung SM, Saltiel AR. 2007 Macrophages block insulin action in adipocytes by altering expression of signaling and glucose transport proteins. Am. J. Physiol. Endocrinol. Metab. 292, E166-E174. (doi:10.1152/ajpendo.00284.2006)

64. Castoldi A, De Souza CN, Saraiva Câmara N0, Moraes-Vieira PM. 2016 The macrophage switch in obesity development. Front. Immunol. 6, 1-11.

65. Gharib SA, McMahan RS, Eddy WE, Long ME, Parks WC, Aitken ML, Manicone AM. 2019 Transcriptional and functional diversity of human macrophage repolarization. J. Allergy Clin. Immunol. 143, 1536-1548. (doi:10.1016/j.jaci. 2018.10.046)

66. Sharma $\mathrm{M}$ et al. 2019 Netrin-1 alters adipose tissue macrophage fate and function in obesity. Immunometabolism 1, 1-26.

67. Henao-Mejia J, Elinav E, Thaiss CA, Flavell RA. 2014 Inflammasomes and metabolic disease. Annu. Rev. Physiol. 76, 57-78. (doi:10.1146/annurev-physiol021113-170324)

68. De Nardo D, Latz E. 2011 NLRP3 inflammasomes link inflammation and metabolic disease. Trends Immunol. 32, 373-379. (doi:10.1016/j.it.2011.05. 004)

69. Rheinheimer J, de Souza BM, Cardoso NS, Bauer AC, Crispim D. 2017 Current role of the NLRP3 inflammasome on obesity and insulin resistance: a systematic review. Metabolism 74, 1-9. (doi:10. 1016/.j.metabol.2017.06.002)

70. Haneklaus M, O'Neill LAJ. 2015 NLRP3 at the interface of metabolism and inflammation. Immunol. Rev. 265, 53-62. (doi:10.1111/imr.12285)

71. Mastrocola R, Aragno M, Alloatti G, Collino M, Penna C, Pagliaro P. 2017 Metaflammation: tissue-specific alterations of the NLRP3 inflammasome platform in metabolic syndrome. Curr. Med. Chem. 25, 1294-1310. (doi:10.2174/0929867324666170407123522) 
72. Vandanmagsar B et al. 2011 The NLRP3 inflammasome instigates obesity-induced inflammation and insulin resistancce. Nat. Med. 17, 179-188.

73. Stienstra $R$ et al. 2011 Inflammasome is a central player in the induction of obesity and insulin resistance. Proc. Natl Acad. Sci. USA 108, 15 324-15 329. (doi:10.1073/pnas.1100255108)

74. Xu C et al. 2018 Targeting of NLRP3 inflammasome with gene editing for the amelioration of inflammatory diseases. Nat. Commun. 9, 4092. (doi:10.1038/s41467-018-06522-5)

75. Lee HM, Kim JJ, Kim HJ, Shong M, Ku BJ, Jo EK. 2013 Upregulated NLRP3 inflammasome activation in patients with type 2 diabetes. Diabetes $\mathbf{6 2}$, 194-204. (doi:10.2337/db12-0420)

76. Wernstedt Asterholm I, Tao C, Morley TS, Wang QA, Delgado-Lopez F, Wang ZV, Scherer PE. 2014 Adipocyte inflammation is essential for healthy adipose tissue expansion and remodeling. Cell Metab. 20, 103-118. (doi:10.1016/j.cmet.2014.05. 005)

77. DiSpirito JR, Mathis D. 2015 Immunological contributions to adipose tissue homeostasis. Semin. Immunol. 27, 1-17. (doi:10.1016/j.smim.2015.10. 005)

78. Elks CM, Zhao P, Grant RW, Hang H, Bailey JL, Burk DH, Mcnulty MA, Mynatt RL, Stephens JM. 2016 Loss of oncostatin $M$ signaling in adipocytes induces insulin resistance and adipose tissue inflammation in vivo. J. Biol. Chem. 291, 17 066-17 076. (doi:10. 1074/jbc.M116.739110)

79. Stephens JM, Bailey JL, Hang H, Rittell V, Dietrich MA, Mynatt RL, Elks CM. 2018 Adipose tissue dysfunction occurs independently of obesity in adipocyte-specific oncostatin receptor knockout mice. Obesity 26, 1439-1447. (doi:10.1002/0by. 22254)

80. Zhu Q, An YA, Kim M, Zhang Z, Zhao S, Zhu Y, Asterholm IW, Kusminski CM, Scherer PE. 2020 Suppressing adipocyte inflammation promotes insulin resistance in mice. Mol. Metab. 39, 1-11. (doi:10.1016/j.molmet.2020.101010)

81. Smith SR, Lovejoy JC, Greenway F, Ryan D, De Jonge L, De La Bretonne J, Volafova J, Bray GA. 2001 Contributions of total body fat, abdominal subcutaneous adipose tissue compartments, and visceral adipose tissue to the metabolic complications of obesity. Metabolism 50, 425-435. (doi:10.1053/meta.2001.21693)

82. Shai I, Jiang R, Manson JAE, Stampfer MJ, Willett WC, Colditz GA, Hu FB. 2006 Ethnicity, obesity, and risk of type 2 diabetes in women: a 20-year followup study. Diabetes Care 29, 1585-1590. (doi:10. 2337/dc06-0057)

83. Mokdad AH, Ford ES, Bowman BA, Dietz WH, Vinicor F, Bales VS, Marks JS. 2003 Prevalence of obesity, diabetes, and obesity-related health risk factors, 2001. JAMA 289, 76-79. (doi:10.1001/jama. 289.1.76)

84. Muñoz-Garach A, Cornejo-Pareja I, Tinahones FJ. 2016 Does metabolically healthy obesity exist? Nutrients 8, 1-10. (doi:10.3390/nu8060320)
85. Yang $X$ et al. 2017 Switching harmful visceral fat to beneficial energy combustion improves metabolic dysfunctions. JCI Insight 2, e89044. (doi:10.1172/jci. insight.89044)

86. Wu J, Cohen P, Spiegelman BM. 2013 Adaptive thermogenesis in adipocytes: is beige the new brown? Genes Dev. 27, 234-250. (doi:10.1101/gad. 211649.112)

87. Sidossis LS et al. 2015 Browning of subcutaneous white adipose tissue in humans after severe adrenergic stress. Cell Metab. 22, 219-227. (doi:10. 1016/j.cmet.2015.06.022)

88. Razzoli $M$ et al. 2016 Stress-induced activation of brown adipose tissue prevents obesity in conditions of low adaptive thermogenesis. Mol. Metab. 5, 19-33. (doi:10.1016/j.molmet.2015.10.005)

89. Ikeda K, Maretich P, Kajimura S. 2018 The common and distinct features of brown and beige adipocytes. Trends Endocrinol. Metab. 29, 191-200. (doi:10.1016/j.tem.2018.01.001)

90. Luong Q, Huang J, Lee KY. 2019 Deciphering white adipose tissue heterogeneity. Biology (Basel) 8, $1-12$.

91. Lee KY, Luong Q, Sharma R, Dreyfuss JM, Ussar S, Kahn CR. 2019 Developmental and functional heterogeneity of white adipocytes within a single fat depot. EMBO J. 38, e99291. (doi:10.15252/embj. 201899291)

92. Chusyd DE, Wang D, Huffman DM, Nagy TR. 2016 Relationships between rodent white adipose fat pads and human white adipose fat depots. Front. Nutr. 3, 1-12. (doi:10.3389/fnut.2016. 00010)

93. Manolopoulos KN, Karpe F, Frayn KN. 2010 Gluteofemoral body fat as a determinant of metabolic health. Int. J. Obes. 34, 949-959. (doi:10. 1038/ijo.2009.286)

94. van der Poorten D et al. 2008 Visceral fat: a key mediator of steatohepatitis in metabolic liver disease. Hepatology 48, 449-457. (doi:10.1002/hep. 22350)

95. Soo KK et al. 2004 Visceral fat thickness measured by ultrasonography can estimate not only visceral obesity but also risks of cardiovascular and metabolic diseases. Am. J. Clin. Nutr. 79, 593-599. (doi:10.1093/ajcn/79.4.593)

96. Eguchi $Y$ et al. 2006 Visceral fat accumulation and insulin resistance are important factors in nonalcoholic fatty liver disease. J. Gastroenterol. 41, 462-469. (doi:10.1007/s00535-006-1790-5)

97. Fontana L, Eagon JC, Trujillo ME, Scherer PE, Klein S. 2007 Visceral fat adipokine secretion is associated with systemic inflammation in obese humans. Diabetes 56, 1010-1013. (doi:10.2337/db06-1656)

98. Thörne A, Lönnqvist F, Apelman J, Hellers G, Arner P. 2002 A pilot study of long-term effects of a novel obesity treatment: omentectomy in connection with adjustable gastric banding. Int. J. Obes. 26, 193-199. (doi:10.1038/sj.ijo.0801871)

99. Lottati M, Kolka C, Stefanovski D, Kirkamn E, Bergman R. 2009 Greater omentectomy improves insulin sensitivity in non-obese dogs. Obesity 17, 674-680. (doi:10.1038/oby.2008.642)
100. Foster MT, Shi H, Seeley RJ, Woods SC. 2011 Removal of intra-abdominal visceral adipose tissue improves glucose tolerance in rats: role of hepatic triglyceride storage. Physiol. Behav. 104, 845-854. (doi:10.1016/j.physbeh.2011.04.064)

101. Van Pelt RE, Jankowski CM, Gozansky WS, Schwartz RS, Kohrt WM. 2005 Lower-body adiposity and metabolic protection in postmenopausal women. J. Clin. Endocrinol. Metab. 90, 4573-4578. (doi:10. 1210/jc.2004-1764)

102. Foster MT, Softic S, Caldwell J, Kohli R, DeKloet AD, Seeley RJ. 2013 Subcutaneous adipose tissue transplantation in diet-induced obese mice attenuates metabolic dysregulation while removal exacerbates it. Physiol. Rep. 1, 1-12. (doi:10.1002/phy2.15)

103. Foster MT, Shi H, Softic S, Kohli R, Seeley RJ, Woods SC. 2011 Transplantation of non-visceral fat to the visceral cavity improves glucose tolerance in mice: investigation of hepatic lipids and insulin sensitivity. Diabetologia 54, 2890-2899. (doi:10.1007/s00125011-2259-5)

104. Item F, Konrad D. 2012 Visceral fat and metabolic inflammation: the portal theory revisited. Obes. Rev. 13(Suppl. 2), 30-39. (doi:10.1111/j.1467-789X 2012.01035.x

105. Rytka JM, Wueest S, Schoenle EJ, Konrad D. 2011 The portal theory supported by venous drainageselective fat transplantation. Diabetes 60, 56-63. (doi:10.2337/db10-0697)

106. Catalano KJ, Stefanovski D, Bergman RN. 2010 Critical role of the mesenteric depot versus other intra-abdominal adipose depots in the development of insulin resistance in young rats. Diabetes 59, 1416-1423. (doi:10.2337/db08-0675)

107. Abate N, Garg A, Peshock RM, Stray-Gundersen J, Grundy SM. 1995 Relationships of generalized and regional adiposity to insulin sensitivity in men. J. Clin. Invest. 96, 88-98. (doi:10.1172/JCl118083)

108. Goodpaster BH, Thaete FL, Simoneau JA, Kelley DE. 1997 Subcutaneous abdominal fat and thigh muscle composition predict insulin sensitivity independently of visceral fat. Diabetes $\mathbf{4 6}$, 1579-1585. (doi:10.2337/diacare.46.10.1579)

109. Gao H et al. 2019 Lipoatrophy and metabolic disturbance in mice with adipose-specific deletion of kindlin-2. JCI Insight. 4, e128405. (doi:10.1172) jci.insight.128405)

110. Luzi L, Perseghin G, Tambussi G, Meneghini E, Scifo P, Pagliato E, Del Maschio A, Testolin G, Lazzarin A. 2002 Intramyocellular lipid accumulation and reduced whole body lipid oxidation in HIV lipodystrophy. Am. J. Physiol. Endocrinol. Metab. 284, E274-E280. (doi:10.1152/ajpendo.00391.2001)

111. Gavrilova 0, Marcus-Samuels B, Graham D, Kim JK, Shulman Gl, Castle AL, Vinson C, Eckhaus M, Reitman ML. 2000 Surgical implantation of adipose tissue reverses diabetes in lipoatrophic mice. J. Clin. Invest. 105, 271-278. (doi:10.1172/JCl7901)

112. Korenblat K, Fabrinni E, Mohammed S, Klein S. 2008 Liver, muscle, and adipose tissue insulin action is directly related to intrahepatic triglyceride content in obese subjects. Gastroenterology 134, 1369-1375. (doi:10.1053/j.gastro.2008.01.075) 
113. Abildgaard J et al. 2018 Ectopic lipid deposition is associated with insulin resistance in postmenopausal women. J. Clin. Endocrinol. Metab. 103, 3394-3404. (doi:10.1210/jc.2018-00554)

114. van Herpen NA, Schrauwen-Hinderling VB. 2008 Lipid accumulation in non-adipose tissue and lipotoxicity. Physiol. Behav. 94, 231-241. (doi:10. 1016/j.physbeh.2007.11.049)

115. Mingrone G, Rosa G, Greco AV, Manco M, Vega N, Nanni G, Castagneto M, Vidal H. 2003 Intramyocitic lipid accumulation and SREBP-1c expression are related to insulin resistance and cardiovascular risk in morbid obesity. Atherosclerosis 170, 155-161. (doi:10.1016/S0021-9150(03)00254-5)

116. Ouwens DM, Boer C, Fodor M, De Galan P, Heine RJ, Maassen JA, Diamant M. 2005 Cardiac dysfunction induced by high-fat diet is associated with altered myocardial insulin signalling in rats. Diabetologia 48, 1229-1237. (doi:10.1007/500125-005-1755-x)

117. Hegarty BD, Cooney GJ, Kraegen EW, Furler SM. 2002 Increased efficiency of fatty acid uptake contributes to lipid accumulation in skeletal muscle of high fat-fed insulin-resistant rats. Diabetes 51, 1477-1484. (doi:10.2337/diabetes.51.5.1477)

118. Caterson ID, Hubbard V, Bray GA, Grunstein R, Hansen BC, Hong $Y$, Labarthe D, Seidell JC, Smith SC. 2004 Prevention Conference VII: Obesity, a worldwide epidemic related to heart disease and stroke: Group III: worldwide comorbidities of obesity. Circulation 110, 476-483. (doi:10.1161/01. (IR.0000140114.83145.59)

119. Defronzo RA. 2004 Pathogenesis of type 2 diabetes mellitus. Med. Clin. North Am. 88, 787-835. (doi:10.1016/j.mcna.2004.04.013)

120. Abel ED, Peroni 0, Kim JK, Kim Y-B, Boss 0, Hadro E, Minnemann T, Shulman GI, Kahn BB. 2001 Adipose-selective targeting of the GLUT4 gene impairs insulin action in muscle and liver. Nature 409, 729-733. (doi:10.1038/35055575)

121. Blüher M, Michael MD, Peroni OD, Ueki K, Carter N, Kahn BB, Kahn CR. 2002 Adipose tissue selective insulin receptor knockout protects against obesity and obesity-related glucose intolerance. Dev. Cell 3, 25-38. (doi:10.1016/S1534-5807(02)00199-5)

122. Sakaguchi $M$ et al. 2017 Adipocyte dynamics and reversible metabolic syndrome in mice with an inducible adipocyte-specific deletion of the insulin receptor. Cell Metab. 25, 448-462. (doi:10.1016/j. cmet.2016.12.008)

123. Morigny $P$, Houssier M, Mouisel E, Langin D. 2016 Adipocyte lipolysis and insulin resistance. Biochimie 125, 259-266. (doi:10.1016/j.biochi.2015.10.024)

124. Frühbeck $G$, Méndez-Giménez $L$, FernándezFormoso J-A, Fernández S, Rodríguez A. 2014 Regulation of adipocyte lipolysis. Nutr. Res. Rev. 27, 63-93. (doi:10.1017/S095442241400002X)

125. Rockall $A G$, Sohaib $S A$, Evans $D$, Kaltsas $G$, Isidori AM, Monson JP, Besser GM, Grossman AB, Reznek RH. 2003 Hepatic steatosis in Cushing's syndrome: a radiological assessment using computed tomography. Eur. J. Endocrinol. 149, 543-548. (doi:10.1530/eje.0.1490543)
126. Scaroni C, Zilio M, Foti M, Boscaro M. 2017 Glucose metabolism abnormalities in Cushing syndrome: from molecular basis to clinical management. Endocr. Rev. 38, 189-219. (doi:10.1210/er.20161105)

127. Ouchi N, Parker JL, Lugus JJ, Walsh K. 2011 Adipokines in inflammation and metabolic disease. Nat. Rev. Immunol. 11, 85-97. (doi:10.1038/ nri2921)

128. Fasshauer M, Blüher M. 2015 Adipokines in health and disease. Trends Pharmacol. Sci. 36, 461-470. (doi:10.1016/j.tips.2015.04.014)

129. Ouchi $\mathrm{N}$ et al. 1999 Novel modulator for endothelial adhesion molecules: adipocyte-derived plasma protein adiponectin. Circulation 100, 2473-2476. (doi:10.1161/01.CIR.100.25.2473)

130. Lönnqvist $F$, Nordfors $L$, Jansson $M$, Thörne $A$, Schalling M, Arner P. 1997 Leptin secretion from adipose tissue in women: relationship to plasma levels and gene expression. J. Clin. Invest. 99, 2398-2404. (doi:10.1172/JCI119422)

131. Weigle DS, Duell PB, Connor WE, Steiner RA, Soules MR, Kuijper JL. 1997 Effect of fasting, refeeding, and dietary fat restriction on plasma leptin levels. J. Clin. Endocrinol. Metab. 82, 561-565.

132. Ahlma RS, Prabakaran D, Mantzoros C, Qu D, Lowell B, Maratos-Flier E, Flier JS. 1996 Role of leptin in the neuroendocrine response to fasting. Nature. 382, 250-252. (doi:10.1038/382250a0)

133. Halaas JL, Gajiwala KS, Maffei M, Cohen SL, Chait $B T$, Rabinowitz D, Lallone R, Burley S, Friedman J. 1995 Weight-reducing effects of the plasma protein encoded by the obese gene. Science 269, 543-546. (doi:10.1126/science.7624777)

134. Halaas JL, Boozer C, Blair-West J, Fidahusein N, Denton DA, Friedman JM. 1997 Physiological response to long-term peripheral and central leptin infusion in lean and obese mice. Proc. Natl Acad. Sci. USA 94, 8878-8883. (doi:10.1073/pnas.94.16.8878)

135. Pelleymounter MA, Cullen MJ, Baker MB, Hecht $R$, Winters D, Boone T, Collins F. 1995 Effects of the obese gene product on body weight regulation in ob/ob mice. Science 269, 540-543. (doi:10.1126/ science.7624776)

136. Bruijnzeel AW, Corrie LW, Rogers JA, Yamada H. 2011 Effects of insulin and leptin in the ventral tegmental area and arcuate hypothalamic nucleus on food intake and brain reward function in female rats. Behav. Brain Res. 219, 254-264. (doi:10.1016/ j.bbr.2011.01.020)

137. Clément $\mathrm{K}$ et al. $1998 \mathrm{~A}$ mutation in the human leptin receptor gene causes obesity and pituitary dysfunction. Nature 392, 398-401. (doi:10.1038/ 32911)

138. Harris RBS, Zhou J, Redmann SM, Smagin GN, Smith SR, Rodgers E, Zachwieja JJ. 1998 A leptin doseresponse study in obese $(o b / o b)$ and lean $(+/$ ? $)$ mice. Endocrinology 139, 8-19. (doi:10.1210/endo. 139.1.5675)

139. Paz-Filho G, Mastronardi C, Delibasi T, Wong M-L, Licinio J. 2010 Congenital leptin deficiency: diagnosis and effects of leptin replacement therapy.
Arq. Bras. Endocrinol. Metabol. 54, 690-697. (doi:10.1590/50004-27302010000800005)

140. Havel PJ, Kasim-Karakas S, Mueller W, Johnson PR, Gingerich RL, Stern JS. 1996 Relationship of plasma leptin to plasma insulin and adiposity in normal weight and overweight women: effects of dietary fat content and sustained weight loss. J. Clin. Endocrinol. Metab. 81, 4406-4413.

141. Saad MF, Riad-Gabriel MG, Khan A, Sharma A, Michael R, Jinagouda SD, Boyadjian R, Steil GM. 1998 Diurnal and ultradian rhythmicity of plasma leptin: effects of gender and adiposity. J. Clin. Endocrinol. Metab. 83, 453-459.

142. Zhang Y, Scarpace PJ. 2006 The role of leptin in leptin resistance and obesity. Physiol. Behav. 88, 249-256. (doi:10.1016/j.physbeh.2006.05.038)

143. Zhao $S$ et al. 2020 Partial leptin deficiency confers resistance to diet-induced obesity in mice. Mol. Metab. 37, 1-12. (doi:10.1016/j.molmet.2020.100995)

144. Zhao S, Kusminski CM, Elmquist JK, Scherer PE. 2020 Leptin: less is more. Diabetes 69, 823LP-829. (doi:10.2337/dbi19-0018)

145. likuni N, Kwan Lam Q, Lu L, Matarese G, Cava A. 2008 Leptin and inflammation. Curr. Immunol. Rev. 4, 70-79. (doi:10.2174/157339508784325046)

146. Perry RJ, Peng L, Abulizi A, Kennedy L, Cline GW, Shulman GI. 2017 Mechanism for leptin's acute insulin-independent effect to reverse diabetic ketoacidosis. J. Clin. Invest. 127, 657-669. (doi:10. 1172/JC(88477)

147. Steppan CM, Bailey ST, Bhat S, Brown EJ, Banerjee RR, Wright CM, Patel HR, Ahima RS, Lazar MA. 2001 The hormone resistin links obesity to diabetes. Nature 409, 307-312. (doi:10.1038/35053000)

148. Degawa-Yamauchi M, Bovenkerk JE, Juliar BE, Watson W, Kerr K, Jones R, Zhu Q, Considine RV. 2003 Serum resistin (FIZZ3) protein is increased in obese humans. J. Clin. Endocrinol. Metab. 88, 5452-5455. (doi:10.1210/jc.2002-021808)

149. Kim K-H, Zhao L, Moon Y, Kang C, Sul HS. 2004 Dominant inhibitory adipocyte-specific secretory factor (ADSF)/resistin enhances adipogenesis and improves insulin sensitivity. Proc. Natl Acad. Sci. USA 101, 6780-6785. (doi:10.1073/pnas.0305905101)

150. Qi Y, Nie Z, Lee Y-S, Singhal NS, Scherer PE, Lazar MA, Ahima RS. 2006 Loss of resistin improves glucose homeostasis in leptin deficiency. Diabetes 55, 3083-3090. (doi:10.2337/db05-0615)

151. Steppan CM, Wang J, Whiteman EL, Birnbaum MJ, Lazar MA. 2005 Activation of SOCS-3 by resistin. Mol. Cell. Biol. 25, 1569-1575. (doi:10.1128/MCB. 25.4.1569-1575.2005)

152. Banerjee RR et al. 2004 Regulation of fasted blood glucose by resistin. Science 303, 1195-1198. (doi:10.1126/science.1092341)

153. Qatanani M, Szwergold NR, Greaves DR, Ahima RS, Lazar MA. 2009 Macrophage-derived human resistin exacerbates adipose tissue inflammation and insulin resistance in mice. J. Clin. Invest. 119, 531-539. (doi:10.1172/JCl37273)

154. Park HK, Qatanani M, Briggs ER, Ahima RS, Lazar MA. 2011 Inflammatory induction of human resistin 
causes insulin resistance in endotoxemic mice. Diabetes 60, 775-783. (doi:10.2337/db10-1416)

155. Yamauchi T et al. 2003 Cloning of adiponectin receptors that mediate antidiabetic metabolic effects. Nature 423, 762-769. (doi:10.1038/ nature01705)

156. Ruan H, Dong LQ. 2016 Adiponectin signaling and function in insulin target tissues. J. Mol. Cell Biol. 8, 101-109. (doi:10.1093/jmcb/mjw014)

157. Toczylowski $K$ et al. 2019 Plasma concentration and expression of adipokines in epicardial and subcutaneous adipose tissue are associated with impaired left ventricular filling pattern. J. Transl. Med. 17, 1-11. (doi:10.1186/s12967-0192060-7)

158. Berg AH, Combs TP, Du X, Brownlee M, Scherer PE. 2001 The adipocyte-secreted protein Acrp30 enhances hepatic insulin action. Nat. Med. 7, 947-953. (doi:10.1038/90992)

159. Combs TP, Berg AH, Obici S, Scherer PE, Rossetti L. 2001 Endogenous glucose production is inhibited by the adipose-derived protein Acrp30. J. Clin. Invest. 108, 1875-1881. (doi:10.1172/JCl14120)

160. Wang Y, Xu A, Knight C, Xu LY, Cooper GJS. 2002 Hydroxylation and glycosylation of the four conserved lysine residues in the collagenous domain of adiponectin: potential role in the modulation of its insulin-sensitizing activity. J. Biol. Chem. 277, 19 521-19 529. (doi:10.1074/jbc. M200601200)

161. Ceddia RB, Somwar R, Maida A, Fang X, Bikopoulos $G$, Sweeney G. 2005 Globular adiponectin increases GLUT4 translocation and glucose uptake but reduces glycogen synthesis in rat skeletal muscle cells. Diabetologia 48, 132-139. (doi:10.1007/s00125004-1609-y)

162. Yamauchi T et al. 2002 Adiponectin stimulates glucose utilization and fatty-acid oxidation by activating AMP-activated protein kinase. Nat. Med. 8, 1288-1295. (doi:10.1038/nm788)

163. Scherer PE, Williams S, Fogliano M, Baldini G, Lodish HF. 1995 A novel serum protein similar to C1q, produced exclusively in adipocytes. J. Biol.
Chem. 270, 26 746-26 749. (doi:10.1074/jbc.270. 45.26746)

164. Wu X, Motoshima H, Mahadev K, Stalker TJ, Scalia R, Goldstein BJ. 2003 Involvement of AMP-activated protein kinase in glucose uptake stimulated by the globular domain of adiponectin in primary rat adipocytes. Diabetes 52, 1355-1363. (doi:10.2337/ diabetes.52.6.1355)

165. Fu Y, Luo N, Klein RL, Timothy Garvey W. 2005 Adiponectin promotes adipocyte differentiation, insulin sensitivity, and lipid accumulation. J. Lipid Res. 46, 1369-1379. (doi:10.1194/jlr.M400373JLR200)

166. Kumada M et al. 2003 Association of hypoadiponectinemia with coronary artery disease in men. Arterioscler. Thromb. Vasc. Biol. 23, 85-89. (doi:10.1161/01.ATV.0000048856.22331.50)

167. Xu A, Wang Y, Lam KSL, Vanhoutte PM. 2010 Vascular actions of adipokines: molecular mechanisms and therapeutic implications. In Cardiovascular pharmacology (ed. PM Vanhoutte), pp. 229-255. Cambridge, MA: Academic Press.

168. Hui X, Lam KS, Vanhoutte PM, Xu A. 2012 Adiponectin and cardiovascular health: an update. Br. J. Pharmacol. 165, 574-590. (doi:10.1111/j. 1476-5381.2011.01395.x)

169. Shinmura K. 2010 Is adiponectin a bystander or a mediator in heart failure? The tangled thread of a good-natured adipokine in aging and cardiovascular disease. Heart Fail. Rev. 15, 457-466. (doi:10.1007/ s10741-010-9159-5)

170. Slentz CA et al. 2016 Effects of exercise training alone vs a combined exercise and nutritional lifestyle intervention on glucose homeostasis in prediabetic individuals: a randomised controlled trial. Diabetologia 59, 2088-2098. (doi:10.1007/ s00125-016-4051-z)

171. Boule NG et al. 2005 Effects of exercise training on glucose homeostasis. Diabetes Care 28, 108-114. (doi:10.2337/diacare.28.1.108)

172. Kolahdouzi S, Talebi-Garakani E, Hamidian G, Safarzade A. 2019 Exercise training prevents high-fat diet-induced adipose tissue remodeling by promoting capillary density and macrophage polarization. Life Sci. 220, 32-43. (doi:10.1016/j. Ifs.2019.01.037)

173. Stanford KI, Middelbeek RJW, Goodyear L. 2015 Exercise effects on white adipose tissue: beiging and metabolic adaptations. Diabetes 64, 2361-2368. (doi:10.2337/db15-0227)

174. Thomou T et al. 2017 Adipose-derived circulating miRNAs regulate gene expression in other tissues. Nature 542, 450-455. (doi:10.1038/ nature21365)

175. Mori MA et al. 2014 Altered miRNA processing disrupts brown/white adipocyte determination and associates with lipodystrophy. J. Clin. Invest. 124, 3339-3351. (doi:10.1172/JCl73468)

176. Ji C, Guo X. 2019 The clinical potential of circulating microRNAs in obesity. Nat. Rev. Endocrinol. 15, 731-743. (doi:10.1038/s41574-019-0260-0)

177. Kalluri R, LeBleu VS. 2020 The biology, function, and biomedical applications of exosomes. Science 367, eaau6977. (doi:10.1126/science.aau6977)

178. Kita S, Maeda N, Shimomura I. 2019 Interorgan communication by exosomes, adipose tissue, and adiponectin in metabolic syndrome. J. Clin. Invest. 129, 4041-4049. (doi:10.1172/JCl129193)

179. Zhao $\mathrm{H}$ et al. 2018 Exosomes from adipose-derived stem cells attenuate adipose inflammation and obesity through polarizing M2 macrophages and beiging in white adipose tissue. Diabetes $\mathbf{6 7}$, 235-247. (doi:10.2337/db17-0356)

180. Crewe C, Joffin N, Rutkowski JM, Kim M, Zhang F, Towler DA, Gordillo R, Scherer PE. 2018 An endothelial-to-adipocyte extracellular vesicle axis governed by metabolic state. Cell 175, 695-708. (doi:10.1016/j.cell.2018.09.005)

181. Valencak TG, Osterrieder A, Schulz TJ. 2017 Sex matters: the effects of biological sex on adipose tissue biology and energy metabolism. Redox Biol. 12, 806-813. (doi:10.1016/j.redox.2017. 04.012)

182. Chang E, Varghese M, Singer K. 2018 Gender and sex differences in adipose tissue. Curr. Diab. Rep. 18, 1-10. (doi:10.1007/s11892-018-1031-3) 